\title{
Impact of Plant Essential Oils on Microbiological, Organoleptic and Quality Markers of Minimally Processed Vegetables
}

Jorge Gutierrez

Technological University Dublin, Jorge.Gutierrez@tudublin.ie

Paula Bourke

Technological University Dublin, paula.bourke@tudublin.ie

Julien Lonchamp

Technological University Dublin, jacklonch@hotmail.com

See next page for additional authors

Follow this and additional works at: https://arrow.tudublin.ie/schfsehart

Part of the Food Microbiology Commons

\section{Recommended Citation}

Bourke, P. et al. (2009) Impact of Plant Essential oils on microbiological, organoleptic and quality markers of minimally processed vegetables. Innovative Food Science \& Emerging Technologies, Vol.10, Issue 2, Pages 135-296 (April 2009). doi: 10.1016/j.ifset.2008.10.005

This Article is brought to you for free and open access by the School of Food Science and Environmental Health at ARROW@TU Dublin. It has been accepted for inclusion in Articles by an authorized administrator of ARROW@TU Dublin. For more information, please contact arrow.admin@tudublin.ie, aisling.coyne@tudublin.ie, gerard.connolly@tudublin.ie.

Funder: Irish Department of Agriculture and Food as part of the National Development Plan 2000-2006.

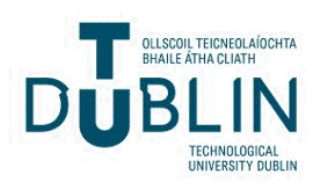


Authors

Jorge Gutierrez, Paula Bourke, Julien Lonchamp, and Catherine Barry-Ryan

This article is available at ARROW@TU Dublin: https://arrow.tudublin.ie/schfsehart/8 

quality markers of minimally processed vegetables”

Jorge Gutierrez, Paula Bourke*, Julien Lonchamp, Catherine Barry-Ryan.

5

6 School of Food Science and Environmental Health, Dublin Institute of Technology, 7 Cathal Brugha Street, Dublin 1, Ireland

8

11 Running title: Microbiological and sensory impact of EO's on ready-to-eat vegetables 12

13 Key words: essential oils, spoilage, sensory, volatiles, lettuce, carrot, ready-to-eat 14

17 * Author for correspondence. Tel: +353-14027594; Fax: +353-14024495; E-mail: Paula.Bourke@dit.ie 18 


\section{Abstract}

25 The objectives of this study were to evaluate the efficacy of plant essential oils

26 (EO's) for control of the natural spoilage microflora on ready-to-eat (RTE) lettuce and

27 carrots whilst also considering their impact on organoleptic properties. Initial

28 decontamination effects achieved using EO's were comparable to that observed with

29 chlorine and solution containing oregano recorded a significantly lower initial TVC level

30 than the water treatment on carrots $(\mathrm{p}<0.05)$. No significant differences were found

31 between the EO treatments and chlorine considering gas composition, color, texture and

32 water activity of samples. The sensory panel found EO treatments acceptable for carrots

33 throughout storage, while lettuce washed with the EO solutions were rejected for overall

34 appreciation by Day 7. Correlating microbial and sensory changes with volatile emissions

35 identified 12 volatile quality markers. Oregano might be a suitable decontamination

36 alternative to chlorine for RTE carrots, while the identification of volatile quality markers

37 is a useful complement to sensory and microbiological assessments in the monitoring of

38 organoleptic property changes and shelf-life of fresh vegetables.

39

40

41

42

43

44

45

46 


\section{1. Introduction}

48 Minimally processed fresh vegetables (MPFV) form an important component of a

49 healthy diet and are a convenient way of increasing fresh produce consumption. Fresh

50 vegetables are susceptible to microbial attack after harvest due to loss of natural

51 resistance and their high water and nutrient content (Ippolito \& Nigro, 2003), a problem

52 which can be exacerbated by minimal processing. MPFV products are normally packaged

53 in modified atmospheres and effective refrigerated temperature control during

54 manufacture, distribution and retailing are required for maintaining the microbiological

55 quality and safety of these products. Unfortunately, these steps do not either eliminate or

56 delay microbial spoilage of these products entirely (Sapers, 2001). The dominating

57 bacterial population on these products during low temperature storage mainly consists of

58 species belonging to the Pseudomonadaceae and Enterobacteriaceae as well as some

59 species belonging to the lactic acid bacteria (LAB) group (Ragaert, Devlieghere \&

60 Debevere, 2007).

61 Disinfection processes incorporating chlorine are often applied to fresh vegetables

62 to enhance safety and shelf-life profiles, but its use has limitations and disadvantages,

63 such as a reduced antimicrobial effectiveness or the possible formation of carcinogenic

64 chlorinated compounds (Li, Brackett, Shewfelt \& Beuchat, 2001; Martin-Diana, Rico,

65 Barry-Ryan, Frias, Henehan \& Barat, 2007). With increased concern about efficacy and

66 toxicological safety of chemicals and synthetic preservatives, the demand for natural

67 alternatives has increased. In this context, plant essential oils (EO’s) are attracting interest

68 for their potential as natural food preservatives as they have Generally Recognised As

69 Safe (GRAS) status and many of them display a wide spectrum of antimicrobial activity, 
70 with potential for control of foodborne pathogens and spoilage bacteria associated with 71 ready-to-eat vegetables (Gutierrez, Rodriguez, Barry-Ryan \& Bourke, 2008a). Oregano

72 (Origanum vulgare L.) and thyme (Thymus vulgaris L.) oils, whose main components are

73 carvacrol and thymol respectively, are characterized by strong antibacterial properties

74 (Dorman \& Deans, 2000; Elgayyar, Draughon, Golden \& Mount, 2001; Burt, 2004;

75 Oussalah, Caillet, Saucier \& Lacroix, 2006; Gutierrez et al., 2008a). However, if EO’s

76 are expected to be widely applied as natural antimicrobials, the organoleptic impact

77 should be considered as the use of naturally derived preservatives can alter the taste of

78 food or exceed acceptable flavor thresholds (Hsieh, Mau \& Huang, 2001; Nazer,

79 Kobilinsky, Tholozana \& Dubois-Brissonneta, 2005). Recently, it was observed that

80 lettuce treated with oregano at $250 \mathrm{ppm}$ was acceptable to a sensory panel as they did not

81 find differences between this lettuce and that washed with chlorinated water (Gutierrez et

82 al., 2008a). Furthermore, the use of oregano combined with thyme normally yields

83 additive antimicrobial effects (Lambert, Skandamis, Coote \& Nychas, 2001; Gutierrez,

84 Barry-Ryan \& Bourke, 2008b), thus, this combination could minimize the concentrations

85 required, thereby reducing sensory impact.

86 MPFV manufacturers are often concerned with sensory improvement. Zhou et al., 87 (2004) defined the shelf life of a green leafy vegetable as the length of time which it can 88 maintain an appearance that appeals to the consumer: crisp green vegetable with little 89 browning or wetness present. Sensory properties such as color, flavor and texture, play a 90 key role in the consumer's choice of fresh prepared products. An issue associated with 91 ready-to-eat vegetables is short shelf-life, which is usually no more than 8 days when 92 stored in adequate conditions (Allende \& Artes, 2003). Beyond day 7 of storage, these 
93 products present off-flavors, tissue softening and proliferation of microorganisms,

94 making them more perishable than untreated material (Watada \& Qui, 1999). Thus,

95 optimizing the application of any novel natural preservation approach to shelf-life

96 extension of MPFV requires that sensory analyses as well as other more objective

97 methods, such as measurement of texture, color or water activity, and volatile emissions

98 analysis are incorporated into the experimental design, in order to monitor possible

99 changes on organoleptic properties. In this context, the identification of quality

100 biomarkers among the volatile emissions from fresh vegetables can help to develop and

101 optimize a rapid quality-monitoring method as well as an understanding of the origin and

102 metabolic basis of volatile emission changes in MPFV during storage (Lonchamp, 2006).

103 Little information is generally known about the relationship between the outgrowth of

104 spoilage microorganisms, their production of metabolites, including volatiles, and the

105 perception of the decay of minimally processed vegetables by consumers (Jacxsens,

106 Devlieghere, Ragaert, Vanneste \& Debevere, 2003).

107 Therefore, the objective of this study was to optimize the application of EO's for

108 MPFV decontamination addressing control of spoilage microflora and improving shelf-

109 life characteristics whilst also considering possible impact on organoleptic properties.

110 Correlations between microbiological data, sensory analysis and volatiles emissions were

111 investigated in order to determine volatile quality biomarkers.

112

\section{2. Materials and methods}

$114 \quad$ Essential oils 
115 The EO's used in this study were oregano (Origanum vulgare) and thyme (Thymus

116 vulgaris). They were selected based on previously reported efficacy (Gutierrez et al. 117 2008a), and were obtained from Guinness Chemical Ltd. (Portlaoise, Ireland) as pure $118 \quad \mathrm{CO}_{2}$ soluble supercritical fluid extracts.

\section{Preparation of vegetable model products}

Iceberg lettuce (Lactuca sativa sp.) and carrots (Daucus carota sp.) were purchased

122 on the day of processing in a local retailer, and stored at $4^{\circ} \mathrm{C}$ until use within 4 hours. To

123 prepare the lettuce, the outer leaves were discarded and cores were removed. Heads were 124 then cut using a stainless steel knife into pieces of approximately 1.5 square inch, to 125 reflect retail packages of salad lettuce. Carrots were peeled and cut into $0.5 \mathrm{~cm}$ thick 126 slices. Three separate treatment solutions were prepared using distilled water at room 127 temperature. The concentrations were $250 \mathrm{ppm}$ for oregano, 125 and $250 \mathrm{ppm}$ for the 128 combined mixture of oregano and thyme, respectively, and $120 \mathrm{ppm}$ for chlorine. 129 Prepared lettuce or carrot was placed in the appropriate treatment solution with gentle 130 manual agitation for $2 \mathrm{~min}$, prior to rinsing in distilled water for $1 \mathrm{~min}$. The ratio of 131 product to treatment solution was 1:10 w/v. Samples were then spin-dried for 6 minutes 132 using an automatic salad spinner at room temperature (Dito Sama, Crypto Peerless, 133 Halifax, UK) and packaged in 150g (lettuce) or 50g (carrot) quantities using $35 \mu \mathrm{m}$-thick 134 oriented-polypropylene (OPP) bags of 20x25cm (Amcor Flexibles Europe, UK). Bags 135 were then sealed using an impulse heat sealer (SMS 350, Packer Products, Basildon, UK) 136 and stored at $4^{\circ} \mathrm{C}$ for 7 days. Unwashed samples and samples treated with distilled water 137 alone were used as controls. 
139 Microbiological analyses were performed on Days 0, 2, 4 and 7. 10g of lettuce or 140 carrots were transferred to Seward stomacher bags with $90 \mathrm{ml}$ of Maximum Recovery

141 Diluent (MRD) and stomached for 2 min on high. Serial dilutions were then prepared in

142 MRD and spread on the following media: (i) Tryptic Soy Agar (TSA, Scharlau Chemie, 143 Spain), for the enumeration of Total Viable Count (TVC); (ii) Man, Rogosa and Sharpe 144 Agar (MRSA, Scharlau Chemie), for Lactic Acid Bacteria (LAB); (iii) Violet Red Bile 145 Dextrose Agar (VRBDA, Scharlau Chemie), for Enterobacteria; (iv) and CN Selective 146 Agar Base (CNA, Scharlau Chemie), for Pseudomonas. Inoculated plates were incubated 147 for $48 \mathrm{~h}$ at $30^{\circ} \mathrm{C}$ (TSA, MRSA and CNA plates) or $37^{\circ} \mathrm{C}$ (VRBDA). Results were 148 expressed as Log CFU/ml. Experiments were performed in duplicate and replicated 149 twice.

$151 \quad$ Quality markers studies

152 Quality parameters were measured from samples treated with EO’s and compared 153 to those obtained using chlorine on Days 1, 4 and 7. Unless otherwise stated, experiments 154 were performed in duplicate and replicated twice. The parameters used were: pack 155 headspace composition, color, texture, water activity, sensory analysis and volatile 156 emission analysis.

157 A gas analyzer (MAPTEST 4000, Hitech Instruments Lts., UK) was used to monitor \% 158 levels of $\mathrm{CO}_{2}$ and $\mathrm{O}_{2}$ in the package during storage. Gas composition was measured using 159 a hypodermic needle inserted through an impermeable patch of polyvinylchloride (PVC) 160 adhesive septum fixed to the bags. 
161 Color measurement was performed using a Color Quest XE colorimeter (Hunter Lab,

162 Northants, UK). The colorimeter was calibrated using a white reference tile $\left(L^{*}=93.97\right.$,

$163 a^{*}=-0.88$ and $b^{*}=1.21$ ) and a light trap (black tile) under illumination conditions. Nine

164 random areas were measured thorough the packaging film, and the three CIELAB color

165 values $\left(L^{*}, a^{*}\right.$ and $\left.b^{*}\right)$ were recorded. The illuminant chosen was D65 and the observer

166 used was $10^{\circ}$. The variable $L^{*}$ (lightness index scale) ranges from 0 for black to 100 for

167 white. The $a^{*}$ scale measures the degree of red $\left(+a^{*}\right)$ or green $\left(-a^{*}\right)$ colors and the $b^{*}$

168 scale measures the degree of yellow $\left(+b^{*}\right)$ or blue $\left(-b^{*}\right)$ colors.

169 Texture properties of lettuce and carrot discs were assessed using an Instron Universal 170 Testing machine model 4464 (Instron Limited, High Wycombe, UK) fitted with a 171 puncture cell. The speed setting for the experiment was $500 \mathrm{~mm} / \mathrm{min}$ and maximum load

172 for the puncture test was expressed in kN. For each treatment, data were obtained from 10

173 (carrot) or 40 (lettuce) pieces from a package and analyzed with the Instron series IX

174 software for Windows.

175 Water activity was measured using the Aqualab Series 3 (Decagon Devices, Pullman, 176 Washington, USA) at $23-24^{\circ} \mathrm{C}$.

$178 \quad 2.5$ Sensory analysis

179 Sensory analysis was performed using a 10 member trained panel with an age range 180 of 25-40 years. The panel consisted of four females and six males who were trained to be 181 familiar with sensory properties of minimally processed lettuce and carrots. The sensory 182 testing method was an acceptance test in which the sensory parameters were scored on a 183 descriptive scale of 1-9. The sensory parameters investigated included the following: (i) 
184 vegetable aroma; (ii) off-odor; (iii) color; (iv) browning; (v) texture; (vi) vegetable taste; 185 (vii) off-after taste; (viii) overall acceptability; and (ix) overall appreciation. Descriptions 186 for each score were as follows: $9=$ like extremely or extremely high, $8=$ like very much 187 or very high, 7 = like moderately or high, $6=$ like slightly or lightly high, $5=$ neither like 188 or dislike or neither high or low, $4=$ dislike slightly or slightly low, $3=$ dislike 189 moderately or low, $2=$ dislike very much or very low, and $1=$ dislike extremely or 190 extremely low. Testing was carried out in sensory analysis booths located adjacent to the 191 processing hall with appropriate lighting conditions and temperature of around $18-20^{\circ} \mathrm{C}$. 192 Results were monitored using the Compusense ${ }^{\circledR}$ Five software (Release 4.4, Ontario, 193 Canada). Sensory trials were replicated twice.

2.6 Volatile emission analysis: Solid-Phase Micro-Extraction (SPME) and Gas chromatography-mass spectrometry (GC/MS) analysis

The package headspace was analyzed using a solid phase micro extraction (SPME)

198 device containing a fiber coated with polydimethylsiloxane (PDMS) film (Supelco, JVA 199 Analytical Ltd., Ireland), following a procedure previously developed and validated using 200 standard compounds in our laboratory (Lonchamp, 2006). Before extraction, an 201 impermeable path of adhesive PVC was attached to each package and a hypodermic 202 needle was used to perforate it. The SPME device was then inserted through the plastic 203 adhesive, and the SPME fiber was exposed for five min and then retracted. The 204 packaging film was resealed using another impermeable patch of PVC.

A Varian 3800 GC (JVA Analytical Ltd., Ireland) with a 2200 Varian ion trap MS 206 was used to analyze the samples. SPME fiber injections were made splitless for 3 min 
207 with the GC injection port temperature held at $250^{\circ} \mathrm{C}$. Grade 5.0 helium, filtered through

208 a Gas Clean GC/MS filter (Varian), was used as the carrier gas at a constant flow rate of

$2092.0 \mathrm{ml} / \mathrm{min}$. Volatile compounds were adsorbed by a fused-silica capillary column (CP-

210 Sil 8, JVA Analytical Ltd., Ireland) with a length of $30 \mathrm{~mm}$, an inner diameter of 0.25

$211 \mathrm{~mm}$ and a $0.25 \mu \mathrm{m}$ film thickness. The initial column oven temperature was set at $30^{\circ} \mathrm{C}$

212 and held at this temperature for $5 \mathrm{~min}$. The temperature was then increased to $250^{\circ} \mathrm{C}$ at a

213 rate of $5^{\circ} \mathrm{C} / \mathrm{min}$ and the final temperature of $250^{\circ} \mathrm{C}$ was maintained for $15 \mathrm{~min}$. MS

214 analysis of the eluted compounds was then carried out using the technique of electron

215 impact ionization. The electron ion source energy used was $70 \mathrm{eV}$ and the mass range

216 chosen was from $40 \mathrm{~m} / \mathrm{z}$ to $350 \mathrm{~m} / \mathrm{z}$. Data were collected using the Varian software and

217 mass spectra of detected compounds were analyzed by library searching in the National

218 Institute of Standards and Technology (NIST) databases. Estimation of the volatile

219 compounds quantity was based on the areas of the peaks detected by MS. The headspace

220 concentration of a volatile compound was then expressed in percentage of total volatile

221 compounds detected or percentage of the total peak area. The compounds were identified

222 with high probabilities when compared with standards from the NIST database (similarity

223 coefficient or reverse similarity coefficient $>85 \%)$. Additional information was obtained

224 for the compounds detected using Flavornet, an online compilation of aroma compounds

225 found in human odor space.

226

$227 \quad 2.7$ Statistical analysis 
229 Means were compared using ANOVA followed by LSD testing at $\mathrm{p}<0.05$ level in order

230 to follow changes over time as well as differences between treatments.

231 Linear regression analysis was used to determine correlations between changes in

232 volatile emissions, sensory properties and bacterial populations. $A R^{2}$ value higher than

2330.90 was considered as indicator of satisfactory correlation between the factors and the

234 volatile compound analyzed was then considered as a marker of the sensory attribute or

235 the changes in bacterial population.

236 Principal component analysis (PCA) was performed using the multivariate method 237 on the Statgraphics software (version 2.1; Statistical Graphics Co., Rockville, USA) to 238 obtain a visual overview of correlations between sensory attributes, microbiological 239 analysis and the volatile markers.

\section{Results and discussion}

2423.1 Effect of EO's and chlorine on the natural microflora of lettuce and carrots

243 Survival of TVC, Enterobacteria, Pseudomonas spp. and LAB on treated lettuce 244 and carrots are indicated in Tables 1 and 2, respectively. The initial effect of EO's on 245 TVC, Enterobacteria and LAB was not significantly different $(\mathrm{p}<0.05)$ to that obtained 246 using chlorine or water. The solution containing oregano recorded a significantly lower 247 initial TVC level than the water treatment on carrots. When oregano was combined with 248 thyme, the effect on bacteria was the same as that observed with the oregano alone $(\mathrm{p}<$ 249 0.05). Thus, from a microbiological point of view, oregano is a viable alternative to 250 chlorine as decontamination treatments. However, all treatments had a minimal 
251 decontamination effect against Pseudomonas and did not maintain the initial decrease in

252 the remainder of the bacterial populations over the storage period. Uyttendaele, Neyts,

253 Vanderswalmen, Notebaert and Debevere (2004) reported that decontamination of carrots

254 with thyme accomplished a significant reduction of the indigenous flora but the

255 psychrotrophic aerobic flora recovered and multiplied during storage time. Bagamboula,

256 Uyttendaele and Debevere (2004) also observed limited reductions in the indigenous

257 flora of lettuce after decontamination treatment with thyme and attributed this to the

258 attachment of the indigenous flora and formation of biofilms on the surface of the lettuce

259 leaves. TVC found on fresh vegetables include a diverse microflora dominated by Gram-

260 negative bacteria, which are generally more resistant to the EO’s than the Gram-positive

261 bacteria (Burt, 2004). In this respect, the combination of EO's with other natural

262 preservation methods as well as the improvement in packaging conditions might prolong

263 shelf-life of minimally processed vegetables.

264 LAB and Enterobacteria were not found above $10^{2} \mathrm{CFU} / \mathrm{ml}$ throughout the storage

265 period on lettuce and carrots, respectively (results not shown). Jacxsens et al. (2003)

266 reported that vegetables containing naturally low concentrations of sugars, such as lettuce

267 or endives, showed a spoilage dominated by Gram-negative microorganisms, while other

268 vegetables with a higher content of carbohydrates, such as bell peppers or celery, suffered

269 from a fast and intense growth of spoilage microorganisms dominated by LAB and

270 yeasts. Furthermore, the growth of LAB did not reach the levels shown by Enterobacteria

271 or Pseudomonas on carrots after 7 days of storage. Klaiber, Baur, Wolf, Hammes and

272 Carle (2005) also observed a limited growth of LAB on minimally processed carrots 
washed with chlorine over 6 days, which was related to the sensitivity of these bacteria to

274 oxygen.

3.2 Quality markers of lettuce and carrots treated with EO's and chlorine

277 The gaseous composition in the bags containing samples washed with the EO 278 solutions were not significantly different $(\mathrm{p}<0.05)$ to those recorded for samples treated 279 with chlorine. The initial conditions inside the OPP bags containing lettuce or carrots 280 were $20.9 \% \mathrm{O}_{2}$ and $0.1 \% \mathrm{CO}_{2}$. After 7 days of storage, the $\mathrm{O}_{2}$ concentration was 281 approximately $12 \%$, while the $\mathrm{CO}_{2}$ concentration increased to $8-9 \%$ in both vegetables 282 type bags. The low concentration of LAB in lettuce could be attributed to these anaerobic 283 conditions, as previously observed by Klaiber et al. (2005), to the decontamination 284 methods used or to a synergistic effect of these two factors.

285 When color measurement was performed, no significant differences in lettuce color 286 values $\left(L^{*} a^{*} b^{*}\right)$ were found between EO treatments and chlorine during the 7 days of 287 storage. With respect to carrots, samples treated with oregano in combination with thyme 288 were significantly $(\mathrm{p}<0.05)$ darker $\left(L^{*}=63.9 \pm 0.6\right)$ than those washed with oregano 289 (61.6 \pm 0.6$)$ or chlorine (62.6 \pm 0.4$)$, but only on Day 1 . During storage at $4^{\circ} \mathrm{C}$ for 7 days, 290 instrumental texture parameters and water activity values did not significantly $(\mathrm{p}<0.05)$ 291 differ between the treatments (Data not shown).

\subsection{Sensory analysis of lettuce and carrots treated with EO's and chlorine} The results of sensory analysis of EO and chlorine treatments are shown in Figure

295 1. Previous studies carried out in our laboratory (Gutierrez et al., 2008a; Gutierrez et al., 
296 2008b) showed that oregano oil was accepted by panelists at $250 \mathrm{ppm}$ and that thyme oil 297 was only rejected at 500 ppm. These two EO's displayed additive anti-microbial effects 298 and the combination of 125 ppm of oregano oil and 250 ppm of thyme aimed at reducing 299 the sensory impact while maintaining the antimicrobial efficacy of the treatment. In this 300 study, carrots treated with oregano and oregano + thyme were accepted throughout the 301 storage period. Both EO treatments were suitable in terms of overall appreciation and no 302 significant differences were found between samples treated with the EO’s and chlorine (p $303<0.05)$. However, on Day 1 the vegetable aroma perceived from samples treated with 304 oregano + thyme was significantly $(\mathrm{p}<0.05)$ less intense than that of oregano or 305 chlorine. In this context, Valero and Giner (2006) observed a positive score for carvacrol 306 but a strong smell and flavor of thymol which minimized the degree of acceptance or 307 liking for carrot broth. The strong effect of thyme on sensory quality of chopped bell 308 peppers was also described by Uyttendaele et al. (2004).

309 For lettuce, samples treated with EO’s and chlorine were accepted throughout the 7 310 days of storage when considering sensory quality. However, lettuce washed with EO’s 311 were unsuitable in terms of overall appreciation by Day 7. The aroma and off-odors 312 perceived from samples treated with EO’s were significantly $(\mathrm{p}<0.05)$ more intense than 313 those of chlorine on Day 1, and the off-after taste of lettuce washed with oregano in 314 combination with thyme was found to be significantly $(\mathrm{p}<0.05)$ stronger that those of 315 oregano or chlorine. By Day 7 samples treated with the EO combination had more intense 316 off-odors than those perceived from lettuce treated with oregano or chlorine. Since the 317 flavor of lettuce is weaker than that displayed by carrots, the sensory impact of EO's 318 could be higher on lettuce. 
3203.4 Volatile emission from lettuce and carrots treated with EO's and chlorine

321 The number of volatiles that were detected and identified in passive MAP lettuce

322 and carrots were 26 and 36, respectively (Table 3). Volatile compounds are secondary

323 metabolites resulting from the degradation of primary metabolites, such as fats and fatty

324 acids, peptides and amino acids, and carbohydrates. Some metabolic pathways produce

325 volatile compounds in unprocessed horticultural produce, but most of them are either

326 enhanced or activated as a consequence of the wound-induced stress following processing

327 (Charron \& Cantliffe, 1995; Choi, Tomas-Barberan \& Salveit, 2005).

328 Terpenes were the main group of detected volatiles and different terpene profiles 329 were found between lettuce and carrots. Eleven terpenes were specific to carrots ( $\alpha$ 330 bergamotene, $\alpha$-caryophyllene, $\alpha$-curcumene, $\alpha$-longipinene, $\beta$-ocimene, $\beta$-pinene, $\delta$ 331 elemene, $\gamma$-muurolene, $\gamma$-terpinene, p-cymene and pyronene), only one was specific to 332 lettuce (dehydro-p-cymene) and ledene was detected from both vegetables. Terpenes are 333 known to contribute to the fresh flavor of many vegetables (Fischer \& Scott, 1997), 334 therefore they are possible markers of the odor profile of ready-to-eat vegetables. Most of 335 the identified terpenes are associated with odor descriptions that are generally accepted 336 by consumers, such as wood, tea, warm, sweet, herb, pine or citrus (Table 3). However, 337 some terpenes were related to off-odor profiles, such as the compounds $\alpha$-longipinene, $\beta$ 338 pinene, $\gamma$-terpinene or $p$-cymene, which are generally perceived as turpentine, gasoline or 339 solvent.

340 A wide variety of volatile organic compounds, including benzoic acids and phenols, 341 are emitted by the shikimic acid pathway and the phenylpropanoid acid pathway, which 
342 are involved in enzymatic browning (Heath \& Reineccius, 1986; Fischer \& Scott, 1997;

343 Tomas-Barberan, Loaiza-Valverde, Bonfanti \& Saltveit, 1997; Gil, Castaner, Fearers,

344 Artes \& Tomas-Barberan, 1998). In this work, 5 phenolic compounds were identified

345 from carrots and lettuce (2,4-bis-1,1-dimethylethylphenol, 2,4-di-t-butyl-6-nitrophenol,

346 4,4,1-methyl-ethyledene-bis-phenol, phenol and butylated hydroxytoluene), while 5-

347 methyl-phenyl-ester-benzoic acid was found from carrots, and 2-octyl-benzoic acid from

348 lettuce and carrots. The odor description of the benzoic acids is associated with flower,

349 honey, herb and sweetness (Table 3), so they may have participated in the development

350 of the aroma perceived from the fresh vegetables.

351 Oxidized phenolics are substrates of polyphenoloxidase, which generates 352 polyphenols, responsible for browning when combined with amino acids to form 353 melanins (Bassil, Makris \& Kefalas, 2005). The ketones detected in this study from both 354 vegetables were 1,3-dehydro-5-methyl-2H-benzimidazol-2-one and 2,3-dehydro-6355 amino-indol-2-one, while pyrovalerone was specific to carrots, and 2,3-dehydro-3,5356 dehydroxy-6-methyl-4H-pyran-4-one and 5-hydroxy-methyl-dehydro-furan-2-one were 357 specific to lettuce.

358 The main products of anaerobic metabolism, such as acetaldehyde or ethanol, are 359 also interesting volatiles since the values of these compounds seem to increase in stressful 360 conditions (Charron \& Cantliffe, 1995; Lopez-Galvez, Peiser, Nie \& Cantwell, 1997). 361 The alcohols 2-phenoxyethanol and cis-geraniol were detected from lettuce and carrots 362 and they are related to odors described as honey, lilac, rose or geranium (Table 3). 4363 methoxy-6,2-propenyl-1,3-benzodioxol was also detected but was specific for carrots 364 treated with oregano in combination with thyme. Increases in alcohol levels during 
365 storage could be caused by fermentative reactions due to high $\mathrm{CO}_{2}$ and/or low $\mathrm{O}_{2}$ 366 concentrations or due to microbiological activity (Ragaert et al., 2007). The

367 microbiological production of alcohol has been shown on a model medium of mixed-

368 lettuce agar (Jacxsens et al., 2003; Ragaert, Devlieghere, Devuyst, Dewulf, Van 369 Langenhove \& Debevere, 2006).

370 Two isocyanates (2-methyl-m-phenylene ester isocyanic acid and 4-methyl-m371 phenylene ester isocyanic acid) and one sulphide (diphenyl sulphide) were identified in 372 the passive MA-packaged lettuce and carrots. These volatiles are usually related to 373 undesirable odors, such as paint, cabbage or sulphur, in agreement with Smith, Song and 374 Cameron (1998), who reported that the presence of dimethyl sulfide in 10 day-old ready375 to-eat lettuce was responsible for the development of a putrid aroma.

\subsection{Volatiles identified as quality markers}

378 Carvacrol and thymol methyl ether were specific to the EO treatments for both 379 vegetables (Table 4). Thymol was detected from lettuce and carrots treated with oregano 380 combined with thyme. For lettuce, the volatiles $\alpha$-caryophyllene, $\beta$-cadinene, $\gamma$-cadinene, 381 caryophyllene oxide and p-cymene were specific to the treatment of oregano in 382 combination with thyme. Caryophyllene oxide and p-cymene were also found from 383 lettuce washed with the solution containing oregano. For carrots, 4-methoxy-6,2384 propenyl-1,3-benzodioxol was specific for the treatment of oregano in combination with 385 thyme. Carvacrol, thymol, caryophyllene and p-cymene are some of the main 386 components of oregano and thyme EO's, and may have contributed to the off-odor and 387 after-taste perceived by the panelists. 
The linear regression and principle components analysis for passive MAP lettuce

389 over the 7 days of storage showed that carvacrol and p-cymene were markers of 390 appreciation difference between chlorine and the EO treatments (Fig. 2A). The volatile

391 ledene and the sensory attribute browning were correlated for all the treatments (Fig. 2A).

392 The losses of aroma, color and texture reported by sensory analysis were related to the 393 increase in TVC, Enterobacteria and Pseudomonas, while the volatiles ledene, 1,3394 dehydro-5-methyl-2H-benzimidazol-2-one, 2-methyl-m-phenylene ester isocyanic acid, 395 thio-amino-butanamide, 2,4-di-t-butyl-6-nitrophenol, $\quad$ and 2,4-bis-1,1396 dimethylethylphenol were found to be quality markers for all the treatments. The volatile 397 quality markers identified for lettuce (Table 4A) were then correlated to both sensory data 398 and microbiological results and the two following clusters were observed: (1) 2,4-di-t399 butyl-6-nitrophenol, 1,3-dehydro-5-methyl-2H-benzimidazol-2-one and texture; (2) 2400 methyl-m-phenylene ester isocyanic acid, off-odor, TVC, Enterobacteria and 401 Pseudomonas (Fig. 3A).

402 Linear regression analysis for passive MAP carrots over the 7 days of storage 403 showed that $\beta$-ocimene was a marker of quality difference between chlorine and EO 404 treatments. 1,3-dehydro-5-methyl-2H-benzimidazol-2-one was also identified as a marker 405 of aroma difference between oregano in combination with thyme and the two other 406 treatments (oregano and chlorine) when PCA complemented linear regression analysis 407 (Fig. 2B). Browning was related to the increase over storage in TVC, LAB and 408 Pseudomonas. The volatiles ledene, $\alpha$-bergamotene, $\alpha$-caryophyllene, $\alpha$-longipinene, 409 1,3-dehydro-5-methtyl-2H-benzimidazol-2-one and thio-amino-butanamide were also 410 correlated to the increase in the spoilage bacteria population and consequently identified 
411 as quality markers for all the treatments. Terpenes are generally synthesized by the 412 mevalonic acid pathway (Logan, Monson \& Potosnak, 2000; Lee, Everts \& Beynen, 413 2004) but also by some microorganisms (Charron \& Cantliffe, 1995). Such a pathway 414 would then be in competition with the plant metabolism for the substrates and 415 intermediates of the mevalonic acid pathway and consequently alter the specific 416 organoleptic properties of fresh vegetables. When the quality marker volatiles for carrots 417 were grouped (Table 4B) and correlated to both sensory data and microbiological results, 418 the three following clusters were obtained: (1) $\alpha$-caryophyllene, browning, TVC, LAB 419 and Pseudomonas; (2) 1,3-dehydro-5-methyl-2H-benzimidazol-2-one, acceptability, 420 appreciation, aroma and color; and (3) ledene and texture (Fig. 3B).

421 In general, the increase in TVC, Enterobacteria, Pseudomonas or LAB was 422 associated with losses of aroma, color and texture as well as with browning. Previous 423 studies reported that some flavor and visual defects can be induced by microbial growth 424 (Carlin, Nguyen-The, Cudennec \& Reich, 1989; King, Magnuson, Torok \& Goodman, 425 1991; Barry-Ryan \& O’Beirne, 1998; Hao, Brackett, Beuchat \& Doyle, 1999). Nguyen426 The and Prunier (1989) also found a relationship between the deterioration of leafy salads 427 and the growth of Pseudomonas spp. More recently, unacceptable changes of appearance 428 during storage of minimally processed artichoke and lettuce has been found due to a 429 psychrotrophic count exceeding 8 log cfu/g (Li et al., 2001; Gimenez, Olarte, Sanz, 430 Lomas, Echavarri \& Ayala, 2003). 
435 The effectiveness of oregano as a decontamination treatment was comparable with that

436 of chlorine. Moreover, when carrots were treated with oregano, the initial TVC

437 concentration was significantly lower than in the water-treated samples. Since passive

438 MAP carrot discs treated with the EO regimes were acceptable in terms of sensory

439 quality and appreciation, oregano could offer a natural alternative for the washing and

440 preservation of MPFV. Furthermore, as plant EO’s are not only considered among the

441 most important natural antimicrobial agents but also have antioxidant and anti-

442 inflammatory activities (Longaray-Delamare, Moschen-Pistorello, Artico, Atti-Serafini \&

443 Echeverrigaray, 2005), they could be employed to extend shelf-life of minimally

444 processed foods as well as confer other benefits to consumers health.

445 However, the application of EO’s on ready-to-eat vegetables requires further studies

446 incorporating additional hurdles such as active MAP as well as extensive sensory

447 screening in order to ensure the overall quality of the product, whilst retaining food

448 safety. The potential nutraceutical properties of EO’s in product application studies also

449 merit further investigation. Although EO’s used in this study might replace or reduce the

450 concentration of chlorine or other chemical preservatives, panelists rejected lettuce

451 washed with the EO treatments at the end of the storage period for overall appreciation.

452 The combination of EO's with other natural preservatives might minimize doses and

453 consequently reduce impact on organoleptic properties of fresh vegetables.

454 A detection method for quality markers of minimally processed vegetables has been

455 developed, based on the volatile emission changes and their correlation with sensory and

456 microbiological analyses. Further studies could include the development of an on-line 
457 quality-monitoring method at industrial level to target specific volatiles, in order to 458 optimize the minimal processing and modified atmosphere packaging, with a view to 459 extending their shelf-life. This could include the development of intelligent or active 460 labels responding to specific changes in concentrations of selected volatile quality 461 markers. Investigation of enzymatic activities may also be of interest to further define the 462 metabolic pathways generating quality-related volatile compounds.

464 Acknowledgments

465 This work was supported by funding from Irish Department of Agriculture and 466 Food as part of the National Development Plan 2000-2006.

\section{$468 \quad$ References}

469 Allende, A., \& Artes, F. (2003). Combined ultraviolet-C and modified atmosphere packaging treatments for reducing microbial growth of fresh processed lettuce. LWT-Food Science and Technology, 36(8), 779-786.

472 Bagamboula, C. F., Uyttendaele, M., \& Debevere, J. (2004). Inhibitory effect of thyme and basil essential oils, carvacrol, thymol, estragol, linalool and p-cymene towards Shigella sonnei and S. flexneri. Food Microbiology, 21, 33-42.

475 Bai, J., Saftner, R. A., \& Watada, A.E. (2003). Characteristics of fresh-cut honeydew 476 (Cucumis xmelo L.) available to processors in winter and summer and its quality 477 maintenance by modified atmosphere packaging. Postharvest Biology and $478 \quad$ Technology, 28, 349-359. 
Barry-Ryan, C., \& O’Beirne, D. (1998). Quality and shelf-life of fresh cut carrot slices as affected by slicing method. Journal of Food Science, 63, 851-856.

Bassil, D., Makris, D. P., \& Kefalas, P. (2005). Oxidation of caffeic acid in the presence of L-cysteine: isolation of 2-S-cysteinylcaffeic acid and evaluation of its antioxidant properties. Postharvest Biology and Technology, 38, 395-402.

Burt, S. (2004). Essential oils: their antibacterial properties and potential applications in foods. International Journal of Food Microbiology, 94(3), 223-253.

Carlin, F., Nguyen-The, C., Cudennec, P., \& Reich, M. (1989). Microbiological spoilage of fresh ready-to-use carrots. Sciences des Aliments, 9, 371-386.

Charron, C. S., \& Cantliffe, D. J. (1995). Volatile emissions from plants. Horticultural reviews, $17,43-72$.

Choi, Y. C., Tomas-Barberan, F. A., \& Salveit, M. E. (2005). Wound-induced phenolic accumulation and browning in lettuce (Lactuca sativa L.) leaf tissue is reduced by exposure to n-alcohols. Postharvest Biology and Technology, 37, 47-55.

Dorman, H. J. D., \& Deans, S. G. (2000). Antimicrobial agents from plants: antibacterial activity of plant volatile oils. Journal of Applied Microbiology, 88, 308-316.

Elgayyar, M., Draughon, F. A., Golden, D. A., \& Mount, J. R. (2001). Antimicrobial activity of essential oils from plants against selected pathogenic and saprophytic microorganisms. Journal of Food Protection, 64(7), 1019-1024.

Fischer, C. \& Scott, T. R. (1997). Flavour compounds. In Food flavours: biology and chemistry (pp. 15-75). Letchworth, UK: RSC Paperbacks.

Gil, M. I., Castaner, M., Fearers, F., Artes, F., \& Tomas-Barberan, F. A. (1998). Modified-atmosphere packaging of minimally processed "Lollo Rosso" (Lactuca 
sativa) - Phenolic metabolites and quality changes. Zeitschrift fur LebensmittelUntersuchung und Forschung, 206, 350-354.

504 Gimenez, M., Olarte, C., Sanz, S., Lomas, C., Echavarri, J. F., Ayala, F. (2003). Relation between spoilage and microbiological quality in minimally processed artichoke packaged with different films. Food Microbiology, 20, 231-242.

507 Gutierrez, J., Rodriguez, G., Barry-Ryan, C., \& Bourke, P. (2008a). Efficacy of plant essential oils against food-borne pathogens and spoilage bacteria associated with ready to eat vegetables: antimicrobial and sensory screening. Journal of Food

Gutierrez, J., Barry-Ryan, C., \& Bourke, P. (2008b). The anti-microbial efficacy of plant essential oil combinations and interactions with food ingredients. International

514 Hao, Y. Y., Brackett, R. E., Beuchat, L. R., \& Doyle, M. P. (1999). Microbiological quality and production of botulinal toxin in film-packaged broccoli, carrots, and

517 Heath, H. B., \& Reineccius, G. (1986). Biogenesis of fruit aroma. In Flavour chemistry and technology (pp 48-49). Basingstoke, UK: MacMillan Publishers Ltd.

519 Hsieh, P-C., Mau, J-L., \& Huang, S-H. (2001). Antimicrobial effect of various 520 combinations of plant extracts. Food Microbiology, 18, 35-43.

521 Ippolito, A. \& Nigro, F. (2003). Natural antimicrobials in postharvest storage of fresh 522 fruits and vegetables. In Natural Antimicrobials for the Minimal Processing of $523 \quad$ Foods (pp 201-223). Roller: Woodhead Publishing LTD. 

between microbiological quality, metabolite production and sensory quality of equilibrium modified atmosphere packaged fresh-cut produce. International Journal of Food Microbiology, 83, 263-280.

King, A. D., Magnuson, J. A., Torok, T., Goodman, N. (1991). Microbial flora and storage quality of partially processed lettuce. Journal of Food Science, 56, 459-461.

Klaiber, R. G., Baur, S., Wolf, G., Hammes, W. P., \& Carle, R. (2005). Quality of minimally processed carrots as affected by warm water washing and chlorination. Innovative Food Science and Emerging Technologies, 6, 351-362.

Lambert, R. J. W., Skandamis, P. N., Coote, P., \& Nychas, G. -J. E. (2001). A study of the minimum inhibitory concentration and mode of action of oregano essential oil, thymol and carvacrol. Journal of Applied Microbiology, 91, 453-462.

536 Lee, K. W., Everts, H., \& Beynen, A. C. (2004). Essential oils in broiler nutrition. International Journal of Poultry Science, 3(12), 738-752.

538 Li, Y., Brackett, R. E., Shewfelt, R. L., \& Beuchat, L.R. (2001). Changes in appearance and natural microflora on iceberg lettuce treated in warm, chlorinated water and then stored at refrigeration temperature. Food Microbiology, 18, 299-308.

541 Logan, B. A., Monson, R. K. \& Potosnak, M. J. (2000). Biochemistry and physiology of 542 foliar isoprene production. Trends in plant science, 5(11), 477-481.

543 Lonchamp, J. (2006). Volatile compounds as quality markers for leafy green ready-to-use 544 vegetables: their identification and determination of origin. $\mathrm{PhD}$ Thesis, Dublin $545 \quad$ Institute of Technology. 
546 Lopez-Galvez, G., Peiser, G., Nie, G. X., \& Cantwell, M. (1997). Quality changes in $547 \quad$ packaged salad products during storage. Zeitschrift fur Lebensmittel-Untersuchung $548 \quad$ und Forschung, 205, 64-72.

549 Longaray Delamare, A. P., Moschen-Pistorello, I. T., Artico, L., Atti-Serafini, \& L., 550 Echeverrigaray, S. (2005). Antibacterial activity of the essential oils of Salvia 551 officinalis L. and Salvia triloba L. cultivated in South Brasil. Food Chemistry, $552 \quad$ 100(2), 603-608.

553 Martín-Diana, A. B., Rico, D., Barry-Ryan, D., Frias, J. M., Henehan G. T. M., \& Barat J. 554 M. (2007). Efficacy of steamer jet-injection as alternative to chlorine in fresh-cut $555 \quad$ lettuce. Postharvest Biology and Technology, 45(1), 97-107.

556 Nazer, A. I., Kobilinsky, A., Tholozana, J. -L., \& Dubois-Brissonneta, F. (2005). 557 Combinations of food antimicrobials at low levels to inhibit the growth of $558 \quad$ Salmonella sv. Typhimurium: a synergistic effect?. Food Microbiology, 22, 391559398

560 Nguyen-The, C. \& Prunier, J. P. (1989). Involvement of Pseudomonas in deterioration of 561 “ready-to-eat” salads. International Journal of Food Science and Technology, 24,

563 Oussalah, M., Caillet S., Saucier L., \& Lacroix, M. (2006). Inhibitory effects of selected 564 plant essential oils on the growth of four pathogenic bacteria: E. coli O157:H7, 565 Salmonella Typhimurium, Staphylococcus aureus and Listeria monocytogenes. $566 \quad$ Food Control, 18(5), 414-420. 
Ragaert, P., Devlieghere, F. \& Debevere, J. (2007). Role of microbiological and physiological spoilage mechanisms during storage of minimally processed vegetables. Postharvest Biology and Technology, 44(3), 185-194.

Ragaert, P., Devlieghere, F., Devuyst, E., Dewulf, J., Van Langenhove, H., \& Debevere, J. (2006). Volatile metabolite production of spoilage micro-organisms on a mixedlettuce agar during storage at $7{ }^{\circ} \mathrm{C}$ in air and low oxygen atmosphere. International Journal of Food Microbiology, 112, 162-170.

Sapers, G. (2001). Efficacy of washing and sanitizing methods for disinfection of fresh fruit and vegetable products. Food Technology and Biotechnology, 39(4), 305-311.

Smith, A. B., Song, J., \& Cameron, A. C. (1998). Modified atmosphere packaged cut lettuce: effect of temperature and $\mathrm{O}_{2}$ partial pressure on respiration and quality. Journal of Agricultural and Food Chemistry, 46, 4556-4562.

Tomas-Barberan, F. A., Loaiza-Velarde, J., Bonfanti, A., \& Saltveit, M. E. (1997). Early wound- and ethylene-induced changes in phenylpropanoid metabolism in harvested lettuce. Journal of the American Society of Horticultural Science, 122(3), 399-404.

Uyttendaele, M., Neyts K., Vanderswalmen, H., Notebaert, E., \& Debevere, J. (2004). Control of Aeromonas on minimally processed vegetables by decontamination with lactic acid, chlorinated water, or thyme essential oil solution. International Journal of Food Microbiology, 90(3), 263-271.

Valero, M, \& Giner, M. J. (2006). Effects of antimicrobial components of essential oils on growth of Bacillus cereus INRA L2104 in and the sensory qualities of carrot broth. International Journal of Food Microbiology, 106(1), 90-94. 

Technology, 15, 201-205.

Zhou T., Harrison, A. D., McKellar, R., Young J. C., Odumeru, J., Piyasena, P., Lu, X., Mercer, D. G., \& Karr, S. (2004). Determination of acceptability and shelf life of ready-to-use lettuce by digital image analysis. Food Research International, 37, 875-881.

595 Flavornet database. http://www.flavornet.org/flavornet.html.

597 Figure Captions

598 Figure 1. Evolution of the sensory profile of lettuce (A) and carrots (B) treated with 599 chlorine $(\longleftarrow)$, oregano $(\longleftarrow$ ), or oregano and thyme ( $\longrightarrow$ ) over 7 days.

600 Different letters signify statistical differences between values $(\mathrm{p}<0.05)$ for each 601 attribute. Descriptions for each score were as follows: 9 = like extremely or extremely 602 high, $8=$ like very much or very high, $7=$ like moderately or high, $6=$ like slightly or 603 lightly high, $5=$ neither like or dislike or neither high or low, $4=$ dislike slightly or 604 slightly low, 3 = dislike moderately or low, 2 = dislike very much or very low, and $1=$ 605 dislike extremely or extremely low. No tasting was carried out at day 7.

606

607 Figure 2. 3-D PCA plots of the volatile quality markers (Y axis) and sensory attributes (X 608 axis) of passive MA-packaged lettuce (A) and carrots (B). Clusters are indicated by 609 circles. Volatiles quality markers included in the graphics are $\alpha$-bergamotene 610 (bergamote), $\alpha$-caryophyllene (humelene), $\alpha$-longipinene (longipine), $\beta$-ocimene 611 (ocimene), 1,3-dehydro-5-methyl-2H-benzimidazol-2-one (azolone), 2-methyl-m- 
612 phenylene ester isocyanic acid (cyanic2), 2,4-bis-1,1-dimethylethylphenol

613 (ethylphenolphenol), 2,4-di-t-butyl-6-nitrophenol (nitrophenol), carvacrol, ledene, and p-

614 cymene (cymene). Judgment and quality are appreciation and acceptability, respectively.

615

616 Figure 3. 3-D PCA plots of the volatile quality markers ( $\mathrm{Z}$ axis), sensory attributes (X 617 axis) and changes in bacterial populations (Y axis) of passive MA-packaged lettuce (A) 618 and carrots (B). Clusters are indicated by circles. Volatiles quality markers included in 619 the graphics are $\alpha$-bergamotene (bergamote), $\alpha$-caryophyllene (humelene), $\alpha$-longipinene 620 (longipine), $\quad \beta$-ocimene (ocimene), 1,3-dehydro-5-methyl-2H-benzimidazol-2-one 621 (azolone), 2-methyl-m-phenylene ester isocyanic acid (cyanic2), 2,4-bis-1,1622 dimethylethylphenol (ethylphenolphenol), 2,4-di-t-butyl-6-nitrophenol (nitrophenol) and 623 ledene. Bacterial populations comprise TVC (tvc), Enterobacteria (entero), Pseudomonas 624 (pseudo) and LAB (lab). Judgment and quality are appreciation and acceptability, 625 respectively.

626 


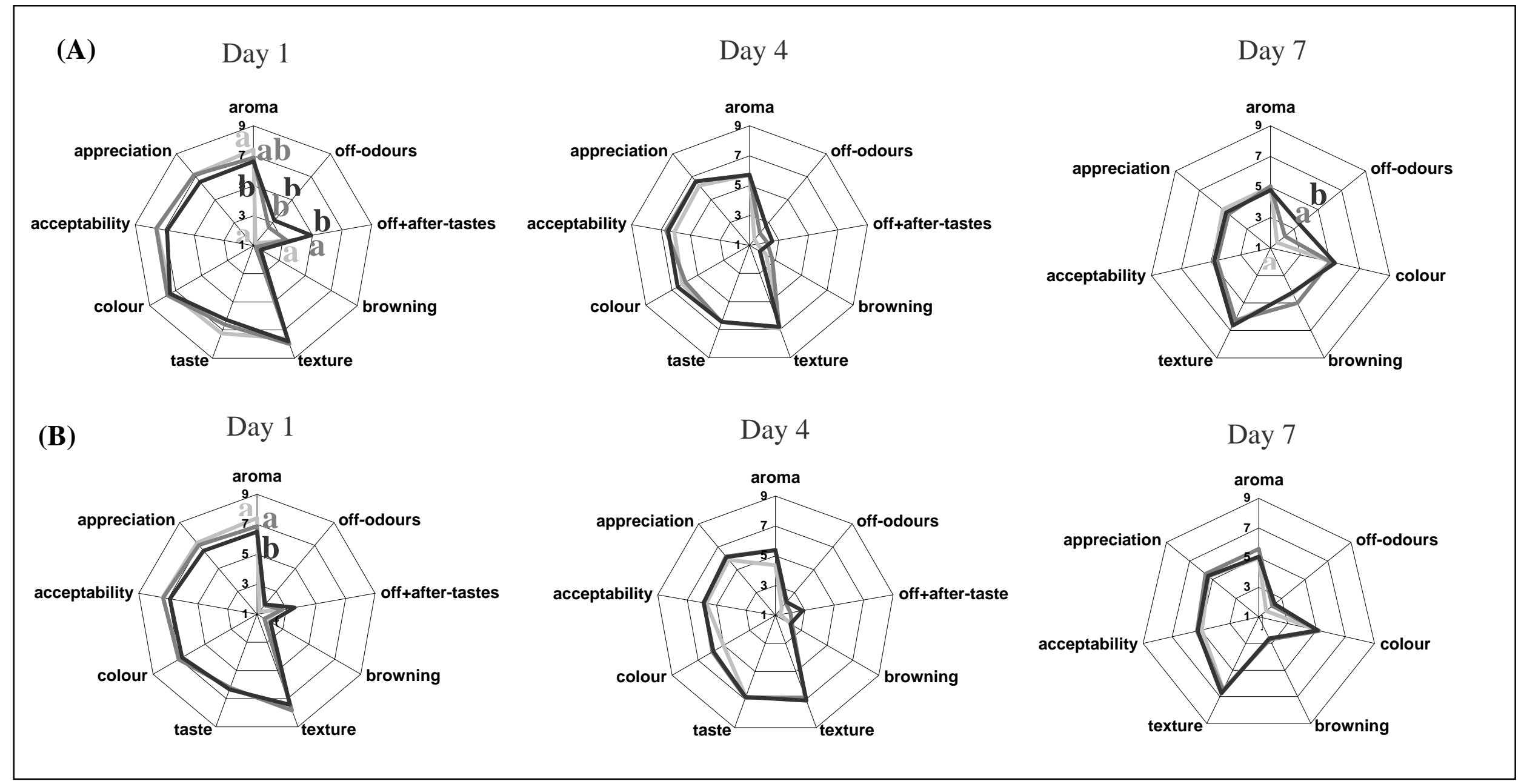

Fig. 1. Evolution of the sensory profile of lettuce $(A)$ and carrots $(B)$ treated with chlorine $(\longrightarrow)$, oregano $(\longrightarrow)$, or oregano and thyme $(\longrightarrow)$ over 7 days. Different letters signify statistical differences between values $(\mathrm{p}<0.05)$ for each attribute. Descriptions for each score were as follows: $9=$ like extremely or extremely high, 8 = like very much or very high, 7 = like moderately or high, $6=$ like slightly or lightly high, $5=$ neither like or dislike or neither high or low, 4 = dislike slightly or slightly low, 3 = dislike moderately or low, 2 = dislike very much or very low, and $1=$ dislike extremely or extremely low. No tasting was carried out at day 7. 

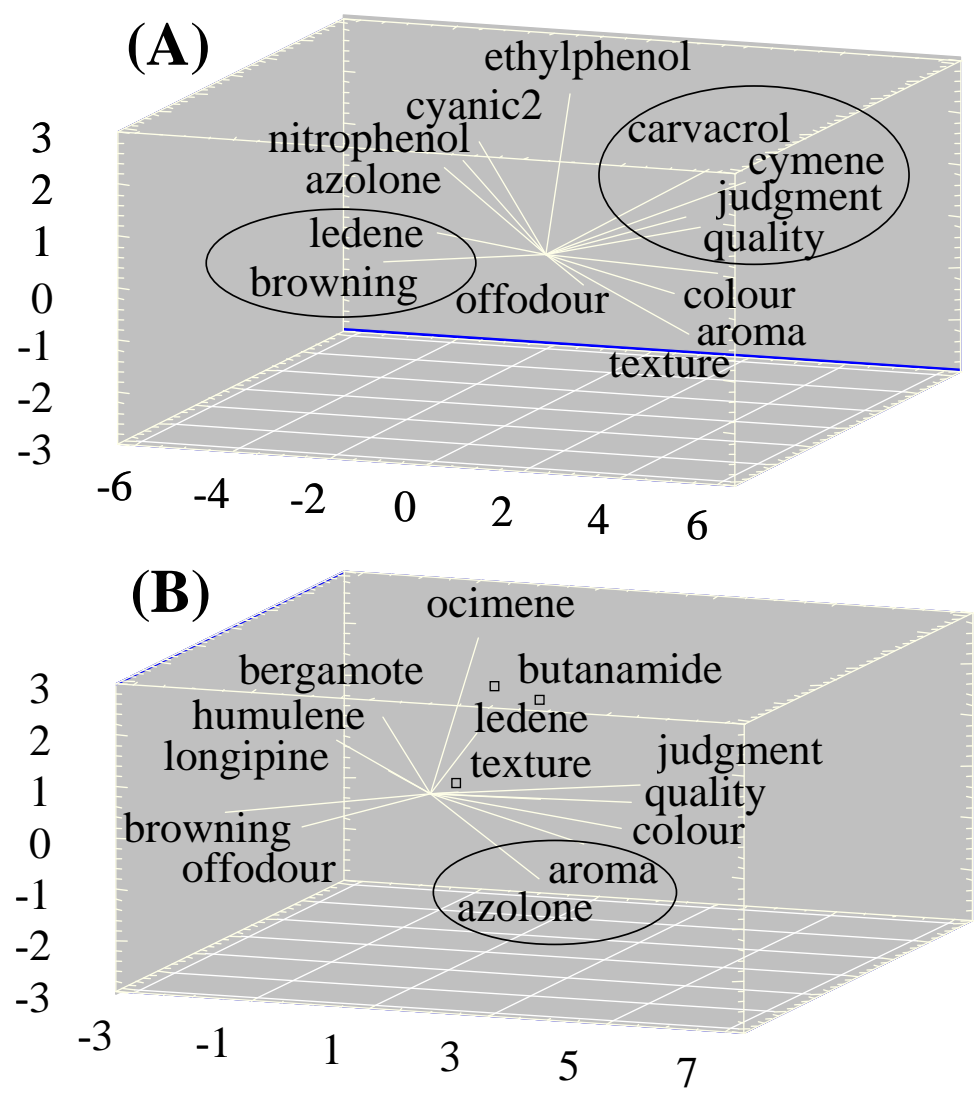

Fig. 2. 3-D PCA plots of the volatile quality markers (Y axis) and sensory attributes (X axis) of passive MA-packaged lettuce (A) and carrots (B). Clusters are indicated by circles. Volatiles quality markers included in the graphics are $\alpha$-bergamotene (bergamote), $\alpha$-caryophyllene (humelene), $\alpha$-longipinene (longipine), $\beta$-ocimene (ocimene), 1,3-dehydro-5-methyl-2Hbenzimidazol-2-one (azolone), 2-methyl-m-phenylene ester isocyanic acid (cyanic2), 2,4-bis-1,1-dimethylethylphenol (ethylphenolphenol), 2,4-di-t-butyl-6-nitrophenol (nitrophenol), carvacrol, ledene, and p-cymene (cymene). Judgment and quality are appreciation and acceptability, respectively. 

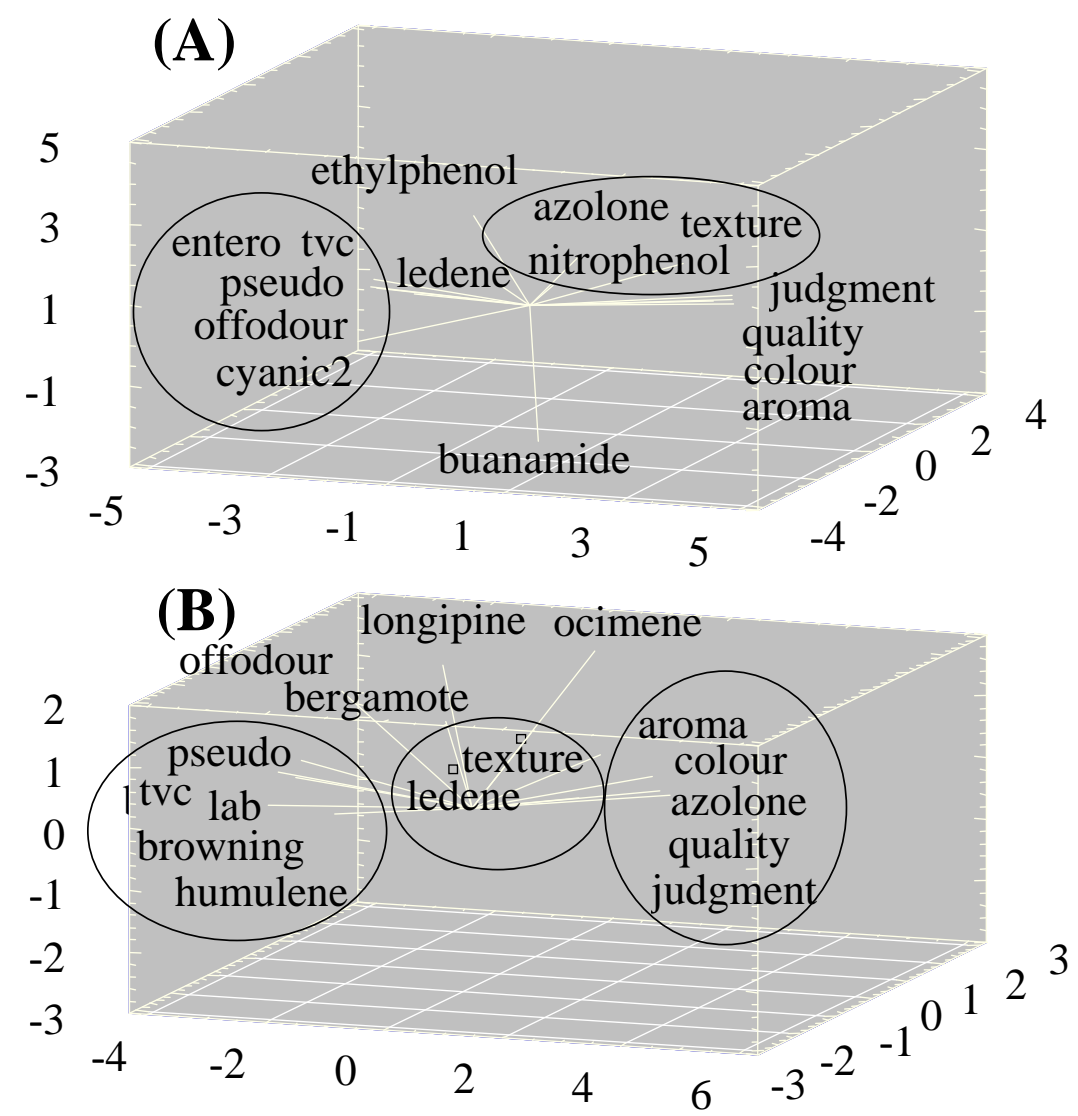

Fig. 3. 3-D PCA plots of the volatile quality markers ( $\mathrm{Z}$ axis), sensory attributes ( $\mathrm{X}$ axis) and changes in bacterial populations (Y axis) of passive MA-packaged lettuce (A) and carrots (B). Clusters are indicated by circles. Volatiles quality markers included in the graphics are $\alpha$-bergamotene (bergamote), $\alpha$-caryophyllene (humelene), $\alpha$-longipinene (longipine), $\beta$-ocimene (ocimene), 1,3-dehydro-5-methyl-2H-benzimidazol-2-one (azolone), 2-methyl-m-phenylene ester isocyanic acid (cyanic2), 2,4-bis-1,1-dimethylethylphenol (ethylphenolphenol), 2,4-di-t-butyl-6-nitrophenol (nitrophenol) and ledene. Bacterial populations comprise TVC (tvc), Enterobacteria (entero), Pseudomonas (pseudo) and LAB (lab). Judgment and quality are appreciation and acceptability, respectively. 
Table 1

Survival of TVC, Enterobacteria and Pseudomonas on prepared lettuce salad treated with EO’s or chlorine

\begin{tabular}{|c|c|c|c|c|c|c|c|c|c|c|c|c|}
\hline \multirow{2}{*}{$\begin{array}{l}\text { Bacterial population } \\
\text { TVC }\end{array}$} & \multicolumn{3}{|c|}{ Day 0} & \multicolumn{3}{|c|}{ Day 2} & \multicolumn{3}{|c|}{ Day 4} & \multicolumn{3}{|c|}{ Day 7} \\
\hline & & & & & & & & & & & & \\
\hline Oregano & 5.12 & \pm 0.10 & $\mathrm{ab}$ & 6.60 & \pm 0.38 & c & 7.64 & \pm 0.44 & $\mathrm{~d}$ & 8.26 & \pm 0.57 & d \\
\hline Oregano + Thyme & 4.96 & \pm 0.04 & $\mathrm{a}$ & 6.29 & \pm 0.15 & c & 7.74 & \pm 0.25 & $\mathrm{~d}$ & 8.16 & \pm 0.59 & d \\
\hline Chlorine & 4.68 & \pm 0.40 & $\mathrm{a}$ & 6.30 & \pm 0.26 & c & 7.17 & \pm 0.44 & $\mathrm{~cd}$ & 7.89 & \pm 0.26 & d \\
\hline Water & 4.91 & \pm 0.02 & $\mathrm{a}$ & 6.10 & \pm 0.31 & bc & 7.50 & \pm 0.23 & $\mathrm{~d}$ & 7.98 & \pm 0.43 & d \\
\hline Untreated & 5.59 & \pm 0.40 & $\mathrm{~b}$ & 6.69 & \pm 0.06 & c & 6.91 & \pm 0.17 & c & 7.41 & \pm 0.09 & d \\
\hline \multicolumn{13}{|l|}{ Enterobacteria } \\
\hline Oregano & 3.27 & \pm 0.21 & $\mathrm{ab}$ & 4.99 & \pm 0.54 & $\mathrm{C}$ & 5.26 & \pm 0.03 & c & 6.20 & \pm 0.27 & $\mathrm{~d}$ \\
\hline Oregano + Thyme & 3.54 & \pm 0.15 & $\mathrm{ab}$ & 4.81 & \pm 0.45 & C & 5.83 & \pm 0.90 & $\mathrm{~cd}$ & 6.12 & \pm 0.49 & d \\
\hline Chlorine & 2.89 & \pm 0.06 & $\mathrm{a}$ & 4.39 & \pm 0.60 & c & 4.97 & \pm 0.54 & $\mathrm{~cd}$ & 5.52 & \pm 0.70 & $\mathrm{~cd}$ \\
\hline Water & 3.82 & \pm 0.62 & bc & 4.94 & \pm 0.40 & c & 5.29 & \pm 0.01 & c & 5.99 & \pm 0.06 & d \\
\hline Untreated & 4.51 & \pm 0.10 & c & 5.30 & \pm 0.74 & C & 5.50 & \pm 0.46 & cd & 6.66 & \pm 0.60 & d \\
\hline \multicolumn{13}{|l|}{ Pseudomonas } \\
\hline Oregano & 2.69 & \pm 0.76 & $\mathrm{a}$ & 5.18 & \pm 0.05 & $\mathrm{~b}$ & 5.96 & \pm 0.06 & bc & 6.89 & \pm 0.27 & c \\
\hline Oregano + Thyme & 3.31 & \pm 0.71 & $\mathrm{a}$ & 5.72 & \pm 0.97 & bc & 6.01 & \pm 0.96 & bc & 6.79 & \pm 0.73 & c \\
\hline Chlorine & 2.28 & \pm 0.74 & $\mathrm{a}$ & 5.40 & \pm 0.29 & $\mathrm{~b}$ & 5.96 & \pm 0.17 & c & 6.51 & \pm 0.36 & c \\
\hline Water & 3.34 & \pm 0.48 & $\mathrm{a}$ & 5.19 & \pm 0.56 & $\mathrm{~b}$ & 6.40 & \pm 0.07 & c & 6.86 & \pm 0.39 & c \\
\hline Untreated & 3.86 & \pm 0.56 & $\mathrm{a}$ & 5.65 & \pm 0.42 & bc & 5.66 & \pm 0.89 & bc & 5.99 & \pm 0.11 & c \\
\hline
\end{tabular}

Counts are expressed in Log $\mathrm{cfu} \mathrm{ml}^{-1}(+/$ - standard deviation). Means followed by different letters are significantly different ( $\mathrm{p}<0.05)$ for each bacterial population. The concentrations used for each treatment were the following: oregano (250 ppm), oregano + thyme (125 ppm + $250 \mathrm{ppm})$, and chlorine (120 ppm). Lettuce washed with distilled water and unwashed lettuce were used as controls. 
Table 2

Survival of TVC, LAB and Pseudomonas on prepared carrot discs treated with EO's or chlorine

\begin{tabular}{|c|c|c|c|c|c|c|c|c|c|c|c|c|}
\hline \multirow{2}{*}{$\begin{array}{l}\text { Bacterial population } \\
\text { TVC }\end{array}$} & \multicolumn{3}{|c|}{ Day 0} & \multicolumn{3}{|c|}{ Day 2} & \multicolumn{3}{|c|}{ Day 4} & \multicolumn{3}{|c|}{ Day 7} \\
\hline & & & & & & & & & & & & \\
\hline Oregano & 3.77 & \pm 0.26 & $\mathrm{a}$ & 3.96 & \pm 0.23 & $\mathrm{a}$ & 5.18 & \pm 0.37 & c & 6.09 & \pm 0.27 & $\mathrm{~d}$ \\
\hline Oregano + Thyme & 4.47 & \pm 0.56 & abc & 4.50 & \pm 0.49 & abc & 5.65 & \pm 0.25 & $\mathrm{~cd}$ & 6.10 & \pm 0.24 & $\mathrm{~d}$ \\
\hline Chlorine & 4.22 & \pm 0.22 & $\mathrm{ab}$ & 4.50 & \pm 0.41 & $\mathrm{ab}$ & 5.22 & \pm 0.22 & $\mathrm{~cd}$ & 5.88 & \pm 0.07 & $\mathrm{~d}$ \\
\hline Water & 4.83 & \pm 0.13 & bc & 5.25 & \pm 0.56 & bc & 6.19 & \pm 0.15 & $\mathrm{~d}$ & 6.63 & \pm 0.15 & $\mathrm{~d}$ \\
\hline Untreated & 5.09 & \pm 0.16 & c & 5.29 & \pm 0.34 & c & 6.33 & \pm 0.46 & $\mathrm{~d}$ & 6.57 & \pm 0.27 & d \\
\hline \multicolumn{13}{|l|}{ LAB } \\
\hline Oregano & 2.39 & \pm 0.01 & $\mathrm{a}$ & 2.94 & \pm 0.69 & $\mathrm{ab}$ & 3.96 & \pm 0.24 & $\mathrm{~b}$ & 3.77 & \pm 0.03 & $\mathrm{~b}$ \\
\hline Oregano + Thyme & 3.14 & \pm 0.44 & $\mathrm{ab}$ & 3.38 & \pm 0.44 & $\mathrm{ab}$ & 3.56 & \pm 0.31 & $\mathrm{~b}$ & 3.55 & \pm 0.37 & $\mathrm{~b}$ \\
\hline Chlorine & 3.30 & \pm 0.56 & $\mathrm{ab}$ & 3.35 & \pm 0.07 & $\mathrm{ab}$ & 3.41 & \pm 0.75 & $\mathrm{~b}$ & 3.68 & \pm 0.56 & $\mathrm{~b}$ \\
\hline Water & 3.20 & \pm 0.65 & $\mathrm{ab}$ & 3.25 & \pm 0.84 & $\mathrm{ab}$ & 3.64 & \pm 0.20 & $\mathrm{~b}$ & 3.14 & \pm 0.37 & $\mathrm{~b}$ \\
\hline Untreated & 3.44 & \pm 0.14 & $\mathrm{~b}$ & 3.18 & \pm 0.82 & $\mathrm{ab}$ & 3.99 & \pm 0.52 & $\mathrm{~b}$ & 3.39 & \pm 0.57 & $\mathrm{~b}$ \\
\hline \multicolumn{13}{|l|}{ Pseudomonas } \\
\hline Oregano & 3.54 & \pm 0.41 & $\mathrm{a}$ & 3.97 & \pm 1.24 & $\mathrm{a}$ & 5.02 & \pm 1.31 & $\mathrm{ab}$ & 5.91 & \pm 1.15 & $\mathrm{~b}$ \\
\hline Oregano + Thyme & 3.43 & \pm 0.93 & $\mathrm{a}$ & 4.55 & \pm 0.33 & $\mathrm{a}$ & 5.27 & \pm 0.69 & $\mathrm{~b}$ & 5.81 & \pm 0.39 & $\mathrm{~b}$ \\
\hline Chlorine & 3.87 & \pm 1.15 & $\mathrm{a}$ & 4.67 & \pm 1.41 & $\mathrm{a}$ & 5.17 & \pm 1.42 & $\mathrm{~b}$ & 5.95 & \pm 1.11 & $\mathrm{~b}$ \\
\hline Water & 3.87 & \pm 1.35 & $\mathrm{a}$ & 4.83 & \pm 1.22 & $\mathrm{a}$ & 5.58 & \pm 1.10 & $\mathrm{ab}$ & 5.82 & \pm 1.30 & $\mathrm{~b}$ \\
\hline Untreated & 4.27 & \pm 1.03 & $\mathrm{a}$ & 4.82 & \pm 0.40 & $\mathrm{a}$ & 5.75 & \pm 0.76 & $\mathrm{ab}$ & 6.01 & \pm 0.43 & $\mathrm{~b}$ \\
\hline
\end{tabular}

Counts are expressed in Log $\mathrm{cfu} \mathrm{ml}^{-1}$ (+/- standard deviation). Means followed by different letters are significantly different (p<0.05) for each bacterial population. The concentrations used for each treatment were the following: oregano (250 ppm), oregano + thyme (125 ppm + $250 \mathrm{ppm})$, and chlorine (120 ppm). Lettuce washed with distilled water and unwashed lettuce were used as controls. 
Table 3

Volatile compounds identified in passive MA-packaged lettuce $(\bullet)$ and carrots $(\boldsymbol{\Delta})$ treated with oregano, oregano with thyme or chlorine

\begin{tabular}{|c|c|c|c|c|c|c|c|c|c|c|}
\hline \multirow{2}{*}{ Volatile compound name } & \multirow{2}{*}{ Odor description ${ }^{\mathrm{a}}$} & \multicolumn{3}{|c|}{ Oregano } & \multicolumn{3}{|c|}{ Oregano + Thyme } & \multicolumn{3}{|c|}{ Chlorine } \\
\hline & & Day 1 & Day 4 & Day 7 & Day 1 & Day 4 & Day 7 & Day 1 & Day 4 & Day 7 \\
\hline$\alpha$-bergamotene & Wood, warm, tea & $\Delta$ & $\Delta$ & $\Delta$ & $\boldsymbol{\Delta}$ & $\boldsymbol{\Delta}$ & $\boldsymbol{\Delta}$ & $\boldsymbol{\Delta}$ & $\Delta$ & $\boldsymbol{\Delta}$ \\
\hline$\alpha$-caryophyllene & Wood & $\boldsymbol{\Delta}$ & $\Delta$ & $\Delta$ & $\Delta \bullet$ & $\Delta$ & $\Delta$ & $\Delta$ & $\Delta$ & $\boldsymbol{\Delta}$ \\
\hline$\alpha$-curcumene & Herb & $\boldsymbol{\Delta}$ & $\boldsymbol{\Delta}$ & $\boldsymbol{\Delta}$ & $\boldsymbol{\Delta}$ & $\boldsymbol{\Delta}$ & $\Delta$ & $\boldsymbol{\Delta}$ & $\boldsymbol{\Delta}$ & $\boldsymbol{\Delta}$ \\
\hline$\alpha$-longipinene & Pine, turpentine & $\boldsymbol{\Delta}$ & $\Delta$ & $\Delta$ & $\Delta$ & $\Delta$ & $\boldsymbol{\Delta}$ & $\boldsymbol{\Delta}$ & $\boldsymbol{\Delta}$ & $\boldsymbol{\Delta}$ \\
\hline$\beta$-cadinene & Thyme, wood & & & & $\bullet$ & $\bullet$ & $\bullet$ & & & \\
\hline$\beta$-ocimene & Sweet, herb & $\Delta$ & $\Delta$ & $\Delta$ & $\Delta$ & $\Delta$ & $\Delta$ & $\Delta$ & $\Delta$ & $\boldsymbol{\Delta}$ \\
\hline$\beta$-pinene & Pine, resin, turpentine & $\boldsymbol{\Delta}$ & & & $\Delta$ & & & $\Delta$ & & \\
\hline$\delta$-elemene & Wood & $\Delta$ & $\Delta$ & $\boldsymbol{\Delta}$ & $\boldsymbol{\Delta}$ & $\Delta$ & $\boldsymbol{\Delta}$ & $\Delta$ & $\Delta$ & $\Delta$ \\
\hline$\gamma$-cadinene & Thyme, wood & & & & $\bullet$ & $\bullet$ & $\bullet$ & & & \\
\hline$\gamma$-muurolene & Herb, wood, spice & $\boldsymbol{\Delta}$ & $\boldsymbol{\Delta}$ & & $\boldsymbol{\Delta}$ & $\boldsymbol{\Delta}$ & & $\boldsymbol{\Delta}$ & $\boldsymbol{\Delta}$ & \\
\hline$\gamma$-terpinene & Gasoline, turpentine & $\boldsymbol{\Delta}$ & $\boldsymbol{\Delta}$ & $\boldsymbol{\Delta}$ & $\boldsymbol{\Delta}$ & $\boldsymbol{\Delta}$ & $\Delta$ & $\boldsymbol{\Delta}$ & $\boldsymbol{\Delta}$ & $\boldsymbol{\Delta}$ \\
\hline 1,3-dehydro-5-methyl-2H-benzimidazol-2-one & Paint & & $\bullet$ & $\Delta \bullet$ & & $\bullet$ & $\Delta \bullet$ & & $\bullet$ & $\Delta \bullet$ \\
\hline 2-diethoxymethyl-1H-imidazole & Fruit & $\Delta \bullet$ & & & & & & $\Delta \bullet$ & & \\
\hline 2-methyl-m-phenylene ester isocyanic acid & Paint & $\Delta \bullet$ & $\Delta \bullet$ & $\Delta \bullet$ & $\Delta \bullet$ & $\Delta \bullet$ & $\Delta \bullet$ & $\Delta$ & $\Delta$ & $\Delta \bullet$ \\
\hline 2-octyl-benzoic acid & Lettuce, herb, sweet & $\Delta \bullet$ & & & $\Delta \bullet$ & & & $\Delta \bullet$ & & \\
\hline 2-phenoxyethanol & Honey, spice, rose, lilac & $\Delta \bullet$ & $\Delta \bullet$ & $\Delta \bullet$ & $\Delta \bullet$ & $\Delta \bullet$ & $\Delta \bullet$ & $\Delta \bullet$ & $\Delta \bullet$ & $\Delta \bullet$ \\
\hline $\begin{array}{l}\text { 2,3-dehydro-3,5-dehydroxy-6-methyl-4H- } \\
\text { pyran-4-one }\end{array}$ & Caramel & $\bullet$ & $\bullet$ & & $\bullet$ & $\bullet$ & & $\bullet$ & $\bullet$ & \\
\hline 2,3-dehydro-6-amino-indol-2-one & Mothball, burnt & $\Delta \bullet$ & $\Delta \bullet$ & $\Delta \bullet$ & $\Delta \bullet$ & $\Delta \bullet$ & $\Delta \bullet$ & $\Delta \bullet$ & $\Delta \bullet$ & $\Delta \bullet$ \\
\hline 2,4-bis-1,1-dimethylethylphenol & Phenol & $\Delta \bullet$ & $\Delta \bullet$ & $\Delta \bullet$ & $\Delta \bullet$ & $\Delta \bullet$ & $\Delta \bullet$ & $\Delta \bullet$ & $\Delta \bullet$ & $\Delta \bullet$ \\
\hline 2,4-di-t-butyl-6-nitrophenol & Sweet & $\Delta \bullet$ & $\Delta \bullet$ & $\Delta \bullet$ & $\Delta \bullet$ & $\Delta \bullet$ & $\Delta \bullet$ & $\Delta \bullet$ & $\Delta \bullet$ & $\Delta \bullet$ \\
\hline 4-methoxy-6,2-propenyl-1,3-benzodioxol & Spice & & & & & $\boldsymbol{\Delta}$ & $\boldsymbol{\Delta}$ & & & \\
\hline
\end{tabular}

${ }^{\bar{a}}$ Compound odour reported in the database http://www.flavornet.org. Volatiles compounds identified in MA-packaged lettuce and carrots are indicated with circles and triangles, respectively. 
Table 3 (Continued)

Volatile compounds identified in passive MA-packaged lettuce $(\bullet$ ) and carrots $(\boldsymbol{\Delta})$ treated with oregano, oregano with thyme or chlorine

\begin{tabular}{|c|c|c|c|c|c|c|c|c|c|c|}
\hline \multirow{2}{*}{ Volatile compound name } & \multirow{2}{*}{ Odor description ${ }^{\mathrm{a}}$} & \multicolumn{3}{|c|}{ Oregano } & \multicolumn{3}{|c|}{ Oregano + Thyme } & \multicolumn{3}{|c|}{ Chlorine } \\
\hline & & Day 1 & Day 4 & Day 7 & Day 1 & Day 4 & Day 7 & Day 1 & Day 4 & Day 7 \\
\hline 4-methyl-1,3-benzene-diamine & Paint & & & $\Delta \bullet$ & & & $\Delta \bullet$ & & & $\Delta \bullet$ \\
\hline 4-methyl-m-phenylene ester isocyanic acid & Paint & $\Delta \bullet$ & $\Delta \bullet$ & $\Delta \bullet$ & $\Delta \bullet$ & $\Delta \bullet$ & $\Delta \bullet$ & $\Delta \bullet$ & $\Delta \bullet$ & $\Delta \bullet$ \\
\hline $\begin{array}{l}\text { 4,4,1-methyl-ethyledene-bis-phenol } \\
\text { 5-methyl-phenyl-ester-benzoic acid }\end{array}$ & $\begin{array}{l}\text { Not described } \\
\text { Flower, honey }\end{array}$ & $\Delta \bullet$ & $\Delta \bullet$ & $\Delta \bullet$ & $\Delta \bullet$ & $\Delta \bullet$ & $\Delta \bullet$ & $\Delta \bullet$ & $\Delta \bullet$ & $\Delta \bullet$ \\
\hline $\begin{array}{l}\text { 5-hydroxy-methyl-dehydro-furan-2-one } \\
\text { Butylated hydroxytoluene }\end{array}$ & $\begin{array}{l}\text { Spice } \\
\text { Phenol }\end{array}$ & & $\bullet$ & $\boldsymbol{\Delta}$ & & $\bullet$ & $\Delta$ & & $\bullet$ & $\Delta$ \\
\hline Caryophyllene oxide & Wood & $\Delta \bullet$ & $\Delta \bullet$ & $\Delta \bullet$ & $\Delta \bullet$ & $\Delta \bullet$ & $\Delta \bullet$ & $\Delta$ & $\Delta$ & $\boldsymbol{\Delta}$ \\
\hline Carvacrol & Citrus, warm & $\Delta \bullet$ & $\Delta \bullet$ & $\Delta \bullet$ & $\Delta \bullet$ & $\Delta \bullet$ & $\Delta \bullet$ & & & \\
\hline Cis-geraniol & Rose, geranium & $\Delta \bullet$ & $\Delta$ & & $\Delta \bullet$ & $\Delta$ & & $\Delta \bullet$ & $\Delta$ & \\
\hline Dehydro-p-cymene & Citrus, pine & $\bullet$ & & & $\bullet$ & & & $\bullet$ & & \\
\hline $\begin{array}{l}\text { Diphenyl sulphide } \\
\text { Isobornyl formate }\end{array}$ & $\begin{array}{l}\text { Cabbage, sulphur } \\
\text { Green, earth, camphor }\end{array}$ & $\dot{\Delta} \bullet$ & $\Delta \bullet$ & $\Delta \bullet$ & $\dot{\Delta} \bullet$ & $\Delta \bullet$ & $\Delta \bullet$ & $\Delta \bullet$ & $\Delta \bullet$ & $\Delta \bullet$ \\
\hline Ledene & Not described & $\Delta \bullet$ & $\Delta \bullet$ & $\Delta \bullet$ & $\Delta \bullet$ & $\Delta \bullet$ & $\Delta \bullet$ & $\Delta \bullet$ & $\Delta \bullet$ & $\Delta \bullet$ \\
\hline p-cymene & Solvent, gasoline, citrus & $\Delta \bullet$ & $\Delta \bullet$ & $\boldsymbol{\Delta}$ & $\Delta \bullet$ & $\Delta \bullet$ & $\boldsymbol{\Delta}$ & $\boldsymbol{\Delta}$ & $\boldsymbol{\Delta}$ & $\boldsymbol{\Delta}$ \\
\hline Phenol & Phenol & $\boldsymbol{\Delta}$ & $\boldsymbol{\Delta}$ & & $\Delta$ & $\boldsymbol{\Delta}$ & & $\boldsymbol{\Delta}$ & $\Delta$ & \\
\hline Pyrovalerone & Wet & $\boldsymbol{\Delta}$ & $\boldsymbol{\Delta}$ & $\boldsymbol{\Delta}$ & $\mathbf{\Delta}$ & $\boldsymbol{\Delta}$ & $\boldsymbol{\Delta}$ & $\boldsymbol{\Delta}$ & $\Delta$ & $\Delta$ \\
\hline Pyronene & Wood, wet & $\Delta$ & $\Delta$ & $\Delta$ & $\boldsymbol{\Delta}$ & $\Delta$ & $\Delta$ & $\Delta$ & $\Delta$ & $\Delta$ \\
\hline Thio-amino-butanamide & Not described & $\Delta \bullet$ & $\Delta \bullet$ & $\Delta \bullet$ & $\Delta \bullet$ & $\Delta \bullet$ & $\Delta \bullet$ & $\Delta \bullet$ & $\Delta \bullet$ & $\Delta \bullet$ \\
\hline Thymol & Citrus, warm, mint & & & & $\Delta \bullet$ & $\Delta \bullet$ & $\Delta \bullet$ & & & \\
\hline Thymol methyl ether & Herbal & $\Delta \bullet$ & & & $\Delta \bullet$ & $\Delta$ & $\Delta$ & & & \\
\hline
\end{tabular}

${ }^{a}$ Compound odour reported in the database http://www.flavornet.org. Volatiles compounds identified in MA-packaged lettuce and carrots are indicated with circles and triangles, respectively. 
Table 4

Evolution of quality markers of passive MA-packaged lettuce (A) or carrots (B) treated with oregano, oregano with thyme or chlorine over 7 days of storage



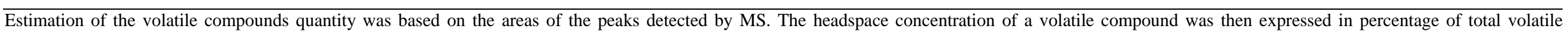
compounds detected or percentage of the total peak area (+/- standard deviation). 